\title{
How to select stimuli for environmental sound research and where to find them
}

\author{
VALERIY SHAFIRO \\ Rush University Medical Center, Chicago, Illinois \\ and \\ BRIAN GYGI \\ East Bay Institute for Research and Education, Martinez, California
}

\begin{abstract}
A major methodological challenge in environmental sound research is to select appropriate stimuli. When an experiment involves a large number of sound sources, making custom recordings or producing sounds live is frequently impractical or, for certain sounds, impossible. Existing databases of environmental sound recordings provide a researcher with a useful alternative. However, finding and selecting suitable sounds in such databases can be difficult because of the great variety of sounds present, poor documentation, questionable recording quality, and required purchasing costs. This article describes a number of practical issues to consider during the stimulus selection process, offers a preliminary compilation of existing resources for obtaining environmental sound recordings, provides some normative perceptual data that can be used as a reference for selecting stimuli and evaluating performance, and lists required characteristics and structural aspects of a research-oriented environmental sound database.
\end{abstract}

Over the last several decades, the attention of a growing number of researchers in psychology and related fields has been turning to the perception of familiar environmental sounds other than speech or music (Ballas, 1993; Bjork, 1985; Cabe \& Pittenger, 2000; Carello, Anderson, \& Kunkler-Peck, 1998; Freed, 1990; Marcell, Borella, Greene, Kerr, \& Rogers, 2000; Repp, 1987). Although environmental sound research is still in its infancy, as compared with the relatively well-established fields of speech, music, and psychoacoustic research, it has yielded a number of valuable theoretical insights into the nature of the cognitive factors and neurophysiological processes underlying the perception of distal objects and events through sound (Ballas, 1993; Cycowicz \& Friedman, 1998; Fowler, 1990; Friedman, Cycowicz, \& Gaeta, 2001; Gaver, 1993; Lebrun et al., 2001; Vanderveer, 1979; VanPetten \& Rheinfelder, 1995; Warren \& Verbrugge, 1984) and has provided a base for developing several practical applications, including new approaches to audiological evaluations (Myers, Letowski, Abouchacra, Kalb, \& Haas, 1996), virtual reality sound synthesis interfaces (Cook, 2002), and automatic sound source recognition in multiple source environments (Ellis, 1996).

We thank James Jenkins and an anonymous reviewer for their helpful comments and suggestions about this article. This work was supported in part by NIH-NIDCD Grant F31 DC006109-01. Correspondence concerning this article should be addressed to V. Shafiro, Department of Communication Disorders and Sciences, Rush University Medical Center, 1015 Armour Academic Center, 1653 W. Congress Parkway, Chicago, IL 60612 (e-mail: valeriy_shafiro@rush.edu).
One of the major methodological challenges in conducting environmental sound research is in finding and selecting stimuli appropriate for a given project. Given the virtually infinite variety of environmental sounds and the lack of a reliable perceptually based classification or even a description of a representative set, it is usually far from clear which stimuli are the most appropriate to include in a test. Other difficulties stem from the paucity of normative behavioral data, variability in the methods and stimuli used in previous research, and the lack of agreed-upon criteria for evaluating stimulus quality and suitability for a particular experimental task. Consequently, investigators entering the field often have to repeat a search for environmental sound resources from scratch and develop their own guidelines for stimulus selection. This task requires a researcher to have sufficient expertise in several technical areas, such as digital signal processing and recording techniques, which may not, in and of themselves, have any relevance to the goals of the intended project. Other drawbacks of this approach are the redundancy in the time and effort needed to find the necessary information (which has been found by others before), further idiosyncrasy in experimental stimuli, and occasional unwanted "surprises" in the quality or availability of otherwise suitable stimuli that are not immediately apparent.

Depending on the goals of a particular study, it is sometimes desirable and practical to present listeners with environmental sounds as they are being naturally produced (Carello et al., 1998; Kunkler-Peck \& Turvey, 2000) or to record sounds specifically for a project (Li, Logan, \& Pastore, 1991; Repp, 1987; Warren \& Verbrugge, 1984). However, producing sounds in real time or custom field 
recording of stimuli is not always possible, especially in studies concerned with listeners' perception of a large number of environmental sounds (Ballas, 1993; Gygi, Kidd, \& Watson, 2004; Marcell et al., 2000; Shafiro, 2004), due to the nature of the sound sources involved and the vast amount of material resources required to make quality recordings. In such cases, researchers tend to turn to already available compilations of environmental sound recordings.

Using existing recordings of environmental sounds as stimuli provides researchers with consistent quality of recordings and greater control over methods of stimulus presentation and permits them to investigate the perception of a greater number of environmental sounds in a single study. Using sounds that are freely available to other researchers allows replication of findings and comparisons between studies. Other advantages consist of saving time, money, and required personnel and, in general, making environmental sound research more feasible and approachable. On the other hand, this approach also has a number of shortcomings and potential pitfalls that may be avoided if brought to the researcher's attention beforehand. In the rest of this article, we will identify known difficulties and pitfalls and suggest ways of preventing them in future studies. Resources for locating environmental sound recording and normative data collected in the authors' previous studies are described in the appendices.

\section{Finding Existing \\ Environmental Sound Recordings}

Technological advances in recording equipment and methods have led to an ever-increasing number of environmental sound recordings being produced for commercial, scientific, archival, and artistic purposes. This growth has been especially apparent during the last several decades, as digital editing, recording equipment, and mass digital storage of recordings have become affordable for small companies and private individuals. The advent of the World-Wide Web and increasingly higher speed broadband access capabilities have substantially simplified the process of sharing and distributing recordings worldwide.

Consequently, a tremendous number of environmental sound recordings have become available to the general public, largely in the form of commercially available CD libraries and electronic databases accessible through the Internet. Available databases vary considerably in cost and in the quantity and quality of available recordings, as well as in the amount of documentation available for each sound. A partial listing of some databases and a brief description of each is provided in Appendix A.

\section{Selecting Environmental Sounds}

What kinds of sounds to select? The main criterion for the selection of environmental sounds as stimuli in an experiment is their suitability for the overall goals of a given study. Practical issues relating to sound quality and database resources, although highly important, should be considered later on in the process of experimental design. Because environmental sound perception is relevant to a large number of theoretical and applied fields, the theoretical constructs and methodological requirements can vary widely depending on the subject population (e.g., children, adults, elderly, hearing impaired, animal, or machine listeners) and the methods used in the study (e.g., detection, identification, recognition, discrimination, or similarity rating). Previous research in the area of interest may be the most valuable guide when choosing specific types of sounds for a study. In general, recorded environmental sounds that have been employed in research thus far can be divided into the following four categories.

1. Isolated multiple sound tokens of the same physical sound source, or of the same type of sound source, have been used in research concerned with listeners' ability to perceive a particular property of the same soundproducing object or event. For instance, researchers asked listeners whether a bottle bounced or broke after a fall (Warren \& Verbrugge, 1984), whether listeners could judge the configuration of two palms during clapping from the sound of the claps (Repp, 1987), or whether the gender of a walker could be determined from the sound of his/her footsteps (Li et al., 1991).

2 . Inventories of variable lengths comprising isolated environmental sounds produced by different sources have been used to investigate identification accuracy (Marcell et al., 2000; Vanderveer, 1979), naming agreement across different listener populations (Fabiani, Kazmerski, Cycowicz, \& Friedman, 1996), and acoustic parameters and cognitive factors (Ballas, 1993; Gygi et al., 2004; Shafiro, 2004) involved in their perception.

3. Temporal sequences of environmental sounds produced by different sources that do not overlap in time with each other have been used to investigate the context effects of the preceding and subsequent sounds (Fowler, 1990) and the ease of learning different sound sequences (Ballas \& Howard, 1987).

4. Mixtures of environmental sounds (a.k.a. auditory scenes), in which sounds from different sources may overlap with one another in time and in frequency, have been used to evaluate the accuracy of source identification by human and machine listeners (Ellis, 1996).

\section{Choosing Sounds From Existing Databases}

Given the multitude of available sources of recordings, it is not always easy to decide which sounds from what database are the most appropriate for a particular project. Examining all existing options, although desirable, may be too expensive, time consuming, and impractical. The following questions are intended to serve as a general guide for evaluating existing databases and the sounds they contain. Although answers to some questions may overlap with others with respect to the information they provide about the sounds in databases, together they will ensure that most crucial aspects of stimulus selection will have been considered. 
1. How many environmental sound types are represented in a database? It is important to check that all types of sounds selected for a project are represented. Simply going by the number of sounds in a database can be misleading, because most or all of the sounds may be various recordings of the same type of sound source (e.g., singing birds or car crashes). However, it is also preferable to have alternative tokens of the same sound sources, since some tokens may be of better quality than others. In addition, having multiple tokens of the same type of sound provides the researcher with an opportunity to test for possible differences in perceiving different tokens of the same environmental sound.

2. How well documented are the recording equipment and setup? Knowing what kind of recording equipment was used can help to evaluate the quality of recordings and can indicate the likelihood of certain recording artifacts, such as a high signal-to-noise $(\mathrm{S} / N)$ ratio or distortions in the sounds' spectra. It is also important to know how the microphone or microphones (for stereo recordings) were mounted, the reverberation characteristics of the space where recordings were made, the distance from the sound source (near or far field), and whether the recorded signal already reflects the head related transfer function. Having recording information can also help to replicate the original study, if necessary. Unfortunately, the details of recording setup usually are not available for most existing environmental sound databases, possibly because this information is of little interest to most consumers.

3. How thoroughly are the sound sources described? Other information of potential value to the researcher is a detailed description of the sound source. For instance, a sound in a database may be labeled simply airplane, or it can describe the airplane's model, whether it is a prop or a jet, or whether it is approaching, taking off, or flying by. Knowing these details may be necessary for projects concerned with differences in perception of different sounds produced by the same type of sound source.

4. (a) What was the original purpose for making a particular recording? (b) Who is the intended consumer of recordings in a database? Recording quality may differ considerably depending on the purpose of the recordings. Although most existing recordings can be used for a variety of purposes, when thorough documentation is lacking, the purpose of making a recording or its intended application can be an indirect indication of the emphasis placed on recording quality. For instance, sounds recorded for use as special effects in computer games or computer animations may have a low sampling rate in order to minimize processing load and storage demands. These sounds would be less likely to have adequate representation of high-frequency information. In addition, Foley sounds (specifically designed effect and imitation sounds frequently used in film and television, which are often included in sound effects collections) may sometimes be provided instead of real-world recordings. Although perceptually such sounds may closely resemble the sounds of actual objects and events (e.g., substituting the sound of coconut halves for that of horse hoofs), the information they contain may be distorted or represent only a caricature of the original sound. Recordings of actual soundproducing objects should always be preferred, unless the comparison of Foley sounds with real sounds is being investigated (Heller \& Wolf, 2002).

5. What editing has been performed after a recording was made? Similarly, sounds recorded for entertainment and special effects are more likely to have been edited after the recording was made. Edited recordings may not represent some information contained in the original sound. Thus, it is important to know what, if any, editing has been performed, and how the originally recorded signal has been modified.

6. When were recordings made, and what was their original storage medium? Some of the sound recordings that are now available in a digital form have been transferred from magnetic tapes and vinyl records recorded several decades ago. These recordings still contain the limitations imposed by the original media (e.g., smaller dynamic range, higher $\mathrm{S} / N$ ratio) or artifacts specific to particular media (e.g., record needle noise). Although this does not necessarily warrant their dismissal from the list of potential stimuli, these limitations need to be appraised during the stimulus selection process.

7. What is the format in which recordings are available now? The question of format is relevant to the issues of compatibility with the stimulus presentation software to be used in the study. Although most standard digital audio formats (e.g., .wav, .aiff, .au., or .mp3) can be easily converted one into another, for other formats conversion tools are not always readily available (e.g., .snd for Neuroscan or many proprietary file formats). In addition, some commonly used digital audio formats involve methods of file compression that may sacrifice information in the signal for increased storage capacity (e.g., MPEG or RealAudio). Recordings available in compressed file formats may still be useful for a particular project, depending on its goals. However, this question needs to be addressed before stimuli are chosen.

8. Have recordings in this database been used in research before? Examination of previous research that employed sounds in a database can be a valuable source of additional information about the quality of the recordings. Although this does not ensure that the sounds in a database are of high quality and previous research might have had different requirements for its stimuli, positive and negative aspects of the recordings might be described in reports or discussed with researchers involved in earlier work with the same recordings. Moreover, if behavioral data have been previously collected on some recordings, it can be supplemented by collecting similar kinds of data on other recordings in the same database or by examining other behavioral measures, using the same stimuli as before.

9. What is the price range for obtaining selected recordings? Prices for existing environmental sound recordings vary widely. Sounds from a number of elec- 
tronic databases can be obtained free of charge (e.g., www.findsounds.com), whereas others may cost from several hundreds to over a thousand dollars (e.g., www. sound-ideas.com; see Appendix A). Higher priced databases often provide more thorough descriptions of the sounds they contain and are, generally, better documented. However, this may not always be the case. It may also be possible to find high-quality sounds without spending a lot of money.

10. Will it be possible to share these recordings with other researchers? Some commercially available recordings cannot be freely redistributed to others, even if only for research purposes. Frequently, recordings advertised as "royalty free" by their manufacturers may be shared with others on a royalty-free basis only if synchronously embedded into a movie track, animation sequence, or computer game. Thus, unless special arrangements can be made with companies selling such recordings, other researchers who would be interested in using these recordings as stimuli will likely need to invest in acquiring rights to the whole database. This becomes an important consideration when recordings from more expensive databases are used. The high cost of a database can become an obstacle for further research work on the stimuli by making it prohibitively expensive for other researchers to use the same recordings as stimuli.

Selecting the right sounds for an environmental sounds study can be a daunting task. The normative data supplied in Appendix B are intended to give some bases for selecting sounds. However, substantially more research is required to create environmental sound tests comparable in methodological rigor to many existing speech, pure tone, or picture tests. Rather than serving as a guide for which types of sounds to use in a study, this article is intended to be a resource for locating appropriate stimuli once the project needs have been determined. The Internet is a powerful tool for accessing free or low-cost sounds, but many of them can be of low quality. Commercial sounds sources can be very costly, and most do not allow distribution of their sounds. It is hoped that the need is clear for an accessible, comprehensive, easily searchable database of low-cost sounds designed specifically for research purposes. The technology to do so exists, and some of the initial groundwork is being laid. A concerted effort of concerned scientists and research funding agencies that see the value of this kind of resource can lead to its completion.

\section{REFERENCES}

Ballas, J. A. (1993). Common factors in the identification of an assortment of brief everyday sounds. Journal of Experimental Psychology: Human Perception \& Performance, 19, 250-267.

Ballas, J. A., \& Howard, J. H. (1987). Interpreting the language of environmental sounds. Environment \& Behavior, 19, 91-114.

BJork, E. A. (1985). The perceived quality of natural sounds. Acustica, 57, 185-188.
Cabe, P. A., \& Pittenger, J. B. (2000). Human sensitivity to acoustic information from vessel filling. Journal of Experimental Psychology: Human Perception \& Performance, 26, 313-324.

Carello, C., Anderson, K. L., \& Kunkler-Peck, A. J. (1998). Perception of object length by sound. Psychological Science, 9, 211-214.

CooK, P. R. (2002). Real sound synthesis for interactive applications. Natick, MA: Peters.

Cycowicz, Y. M., \& Friedman, D. (1998). Effect of sound familiarity on the event-related potentials elicited by novel environmental sounds. Brain \& Cognition, 36, 30-51.

Ellis, D. P. (1996). Prediction-driven computational auditory scene analysis. Unpublished doctoral dissertation, MIT, Cambridge, MA.

Fabiani, M., Kazmerski, V. A., Cycowicz, Y. M., \& Friedman, D. (1996). Naming norms for brief environmental sounds: Effects of age and dementia. Psychophysiology, 33, 462-475.

FowLER, C. A. (1990). Sound-producing sources as objects of perception: Rate normalization and nonspeech perception. Journal of the Acoustical Society of America, 88, 1236-1249.

FreED, D. J. (1990). Auditory correlates of perceived mallet hardness for a set of recorded percussive sound events. Journal of the Acoustical Society of America, 87, 311-322.

Friedman, D., Cycowicz, Y. M., \& Gaeta, H. (2001). The novelty P3: An event-related brain potential (ERP) sign of the brain's evaluation of novelty. Neuroscience \& Behavioral Reviews, 25, 355-373.

GAVER, W. W. (1993). What in the world do we hear? An ecological approach to auditory event perception. Ecological Psychology, 5, 1-29.

GyGi, B., KIDD, G. R., \& WATson, C. S. (2004). Spectral-temporal factors in the identification of environmental sounds. Journal of the Acoustical Society of America, 155, 1252-1265.

Heller, L. M., \& Wolf, L. (2002). When sound effects are better than the real thing [Abstract]. Journal of the Acoustical Society of America, 111, 2339.

Kunkler-Peck, A. J., \& Turvey, M. T. (2000). Hearing shape. Journal of Experimental Psychology: Human Perception \& Performance, 26, 279-294.

Lebrun, N., Clochon, P., Etevenon, P., Lambert, J., Baron, J. C., \& Eustache, F. (2001). An ERD mapping study of the neurocognitive processes involved in the perceptual and semantic analysis of environmental sounds and words. Cognitive Brain Research, 11, 235-248

Li, X., Logan, R. J., \& Pastore, R. E. (1991). Perception of acoustic source characteristics: Walking sounds. Journal of the Acoustical Society of America, 90, 3036-3049.

Marcell, M. M., Borella, D., Greene, M., Kerr, E., \& Rogers, S. (2000). Confrontation naming of environmental sounds. Journal of Clinical \& Experimental Neuropsychology, 22, 830-864.

Myers, L. L., Letowski, T. R., Abouchacra, K. S., Kalb, J. T., $\&$ HaAs, E. C. (1996). Detection and recognition of octave-band sound effects. Journal of the American Academy of Audiology, 7, 346-357.

Owens, E., Kessler, D. K., Raggio, M. W., \& Schubert, E. D. (1985). Analysis and revision of the Minimal Auditory Capabilities (MAC) battery. Ear \& Hearing, 6, 280-290.

REPP, B. H. (1987). The sound of two hands clapping. Journal of the Acoustical Society of America, 81, 1100-1109.

Shafiro, V. (2004). Perceiving the sources of environmental sounds with a varying number of spectral channels. Unpublished doctoral dissertation, City University of New York.

VANDERVEer, N. J. (1979). Ecological acoustics: Human perception of environmental sounds. Dissertation Abstracts International, 40, 4543B.

VanPetten, C., \& Rheinfelder, H. (1995). Conceptual relationships between spoken words and environmental sounds: Event-related brain potential measures. Neuropsychologia, 33, 485-508.

Warren, W. H., \& Verbrugge, R. R. (1984). Auditory perception of breaking and bouncing events. Journal of Experimental Psychology: Human Perception \& Performance, 10, 704-712. 


\section{APPENDIX A}

\section{Some Commercial, Nonprofit, and Private Sources of Environmental Sound Recordings}

The following list is not meant to be comprehensive, but to give researchers an idea of the materials available. Following the links on various Web sites will undoubtedly reveal more and richer resources than we have had time to uncover.

\section{General Sound Effects}

Search engines. In general, search engines will enable you to search on various options and listen to the clips that you get, usually in low-quality $\mathrm{mp} 3$ or streaming audio, to discourage you from recording them through your sound card. Most of them search both commercial and free sites. They give varying information about the clips, which is detailed after every site. As a benchmark, the results of a search for "gun" are included. For the free sounds, recording details are usually not available.

www.findsounds.com. This site only has free sounds, but they do sell software to organize and edit sounds. Search options: sampling rate, bit size, file type, stereo/mono, and file size. All the information above is given about the sound clip, plus a schematic of the waveform, so you can get an idea of the temporal structure of the sound and the number of clipped samples. You can play the sounds in the format specified, which means you can record the high-quality versions. Search of "gun" results: 200 sound clips.

www.sound-effects-library.com. Searches both commercial and free sites. Options exist for a simple keyword search or an advanced search by category, keyword, and length (for which you need to install Shockwave). Apparently, files are available only in 44.1- or 48-kHz sampling rates. A search returns information on description, length, size, stereo/mono, and price. Search of "gun" results: 1,133 sound clips.

http://www.sonomic.com/. Search terms available: category, keywords, library, production company, stereo/mono, or sampling rate ( 44.1 or $48 \mathrm{kHz}$ ). Information returned about the clips: duration, file size, and bit rate (to get the price you must add them to a cart). They do not seem to have free sounds available. Search of "gun" results: over 500 sound clips.

http://www.wavcentral.com/. A site for user-contributed sound effects, so there are largely movie and TV show segments, but some sound effects as well. The legality of these clips is not clear. They are in the process of migrating all clips to .mp3 format. Information provided includes clip size, number of downloads, and users' ratings. Search of "gun" results: 39 sound clips, including a dialogue snippet from The Godfather.

http://labrosa.ee.columbia.edu/dpwe-bin/sfxlist.cgi. A searchable collection of sound effects available from the site of the Laboratory for the Recognition and Organization of Speech and Audio at Columbia University. This collection seems very comprehensive, with a wide selection of different types of environmental sounds. The database can be easily searched by specifying keywords and file parameters. A sample search for "gun" in a 16 bit single channel .wav format with a sampling rate of $22050 \mathrm{~Hz}$ returns 32 matches.

On-line stores. On-line stores sell libraries of sounds but also give you the option of searching for and buying individual commercial sounds, which can get expensive for large numbers of sounds. You can usually listen to low-quality versions of the sounds before buying. Many of them have free sounds for downloading, but often you have to sign up for a newsletter to get them. www.soundfx.com. www.soundeffects.com. www.leonardosoft.com. They only sell libraries on CDs. www.soundeffectslibrary.tv/aboutus.htm

www.ironnerd.com/linkorama/sound.html. Seems to specialize in cartoon effects.

www.sounddogs.com. They have a special section for " $\mathrm{dog}$ pack sounds."

www.ctv.es/USERS/dagullo/misc/sound.htm. A listing of commercially available sound effects CD libraries for entertainment needs, some of which are quite specific (e.g., erotic, steam locomotives, or North American frogs). No search engine is available.

www.stonewashed.net/sfx.html. Links to both free and commercial sites by category, along with descriptions of the sounds available. Many links are broken, and pop-up windows are annoying and make it unpleasant to use.

www.alfreesoundeffects.com. Lots of free sound effects, but some commercial ones for sale (at only $\$ 0.50$ a sound, which is much cheaper than the other commercial sites). The free sounds are of variable quality, but most seem to be 8-bit, mono with low sampling rates.

Commercial sound effects companies. These are all major players in the field and offer extensive, diverse, and well-recorded sounds.

www.renaissancesfx.com.

www.sound-ideas.com.

http://www.tvmusic.com.

www.hollywoodedge.com/the. They have some free sound effects available as mp3s.

\section{Sound effects for clinical applications.}

http://www.auditec.com/ParentFrame.htm. Auditec of St. Louis offers environmental sounds under the heading of "Materials for cochlear implant patients, nonverbal, or difficult to test." Fifteen environmental sounds are available as a part of the standardized Minimal Auditory Capabilities (MAC) Battery (Owens, Kessler, Raggio, \& Schubert, 1985). However, these sounds appear to have a fairly high $\mathrm{S} / N$ ratio, since they were originally recorded in the late 1970 s on cassettes and were only recently transferred to a digital format. Auditec also offers other sound effects packages designed to be used as stimuli for attracting attention and for audiological evaluations of difficult-to-test patients. Other environmental sounds may also be available.

https://web.uvic.ca/psyc/testsale/sound.html. The Sound Recognition Test (SRT) is a closed-set picture-pointing task, designed primarily for nonspeaking children, with three sets of 10 common environmental sounds, plus a practice sound. The sounds are available only on cassette, and information on recording conditions does not seem to be available. The test can be ordered for $\$ 50$. It seems to be also listed in the Auditec catalog as a Sound Effects Recognition Test.

http://cepl.nyspi.org/Resources/Auditory_Stimuli/auditory_ stimuli.html. A site of the New York State Psychiatric Institute containing materials for a study on naming norms for environmental sounds, including links to the sounds (in .snd and .wav format), the scaling factors for normalizing them, and a database of the sounds in Paradox format (Fabiani et al., 1996).

\section{Specialized Sounds}

"Ecological" or ambient sounds. There are a number of sites dedicated to the idea of "acoustic ecology," which is variously defined, but the sites all link to each other. There are some sounds available, along with resources for more information.

www.earthear.com/catalog/index.htm. A Web site and organization dedicated to creative and artistic exploration and pro- 
APPENDIX A (Continued)

motion of awareness of environmental sound. They sell CDs with such titles as "Deep Immersion" and "Beyond the Borders of Home." There are also some on-line samples. The sounds are of a limited practical use for behavioral research, since many of them have been edited, processed, or created for purely aesthetic ends. Some, however, may be useful, depending on the project or questions asked.

www.acousticecology.org. The main Web site for people interested in acoustic ecology, The Acoustic Ecology Institute was founded in 2003 as a spin-off of EarthEar.com. Lots of links, but no on-line samples available.

http://interact.uoregon.edu/MediaLit/WFAE/home. The Web site of the World Forum for Acoustic Ecology, which has many interesting resources, but not much to offer for stimulus selection per se, although there are links to other catalogues.

http://www.naturesounds.org/. A society dedicated to the "preservation, appreciation and creative use of natural sounds." There are links, but no sounds, available on the site.

http://www.soundtracker.com. The Web site for Gordon Hempton, a well-known veteran environmental sound recordist. He will (for a price) supply you with sounds or record sounds you wish to have or give a free consultation on sound projects. No on-line samples.

Animal sound archives. http://birds.cornell.edu/lns. The well-known Macaulay library of natural sounds, which is, as the URL suggests, mostly bird sounds at Cornell University. Reputable research facility that is probably good if you only need bird sounds. No on-line samples, but they sell CDs, and there is a search engine to assemble sounds for downloading.

http://blb.biosci.ohio-state.edu. The Borror Laboratory of Bioacoustics sound archive, "the largest archive of animal sounds in the world." They have some on-line samples, mostly of birds, in Real Audio format, which can be shared. They also give a wealth of information including the species, recording time and place, and recording details. They plan to put their whole catalogue on line.

http://www.bl.uk/collections/sound-archive/cat.html. The British library of sound archives Web site, an enormous library covering music, oral history, drama and literature, dialect, language, and wildlife sounds. You can browse the catalogue, make an appointment for a listening session (in case you are in England), or order copies, all of which are fairly expensive. There are a few on-line snippets available in RealAudio format.

http://www.naturesound.com/corepage/core.html. "Featuring the Sounds of Birds, Frogs, Mammals, and Insects." They sell CDs and have some samples of animal sounds in RealAudio format.

Musical instruments. forumnet.ircam.fr/rubrique.php3?id_ rubrique $=107$. Studio OnLine is a database of over 21,000 instrumental sounds, sampled at different rates and in different formats. Researchers can share samples with other users. Nice interface, but it is costly. Individual, 275 euros; organization, 747 euros. They claim it is possible to order a CD including the sounds of your choice, but the Web site shows no signs of this being the case.

staff.aist.go.jp/m.goto/RWC-MDB. The RWC Music Database is a large-scale music database compiled specifically for research purposes, which contains six original collections of different musical genres. Researchers can use the database for research publications and presentations without copyright restrictions; however, the samples may not be shared. Costs: 9,000 15,000 Japanese yen for each database.

http://theremin.music.uiowa.edu. Iowa Musical Instrument database contains high-quality free samples of several classical musical instruments and, for some reason, a balloon pop. The instruments were recorded in an anechoic chamber. All samples are in mono, 16 bit, $44.1 \mathrm{kHz}$, AIFF format. The exception is the piano, which is recorded in stereo. Researchers may use these samples in research or music projects without restriction.

\section{Miscellany}

http://groups.yahoo.com/group/K5000/files/sharc.tar.Z. SHARC "Sandell Harmonic Archive" is a database of musical timbre information by Gregory Sandell. It has been moved; some sharc material is now on a Yahoo group for the Kawai K5000 synthesizer. You must join Yahoo groups and get approved by the moderator to access it.

http://groups.yahoo.com/group/naturerecordists. A link to a Yahoo discussion group interested in various (mostly technical) issues of environmental sound recordings. 


\section{APPENDIX B}

\section{Identification Accuracy of 60 Band-Limited Familiar Environmental Sounds}

Identification scores for 60 familiar environmental sounds were collected as a part of a larger study (Shafiro, 2004) to serve as a baseline in listeners' identification accuracy in a 60alternative closed-set response task. These accuracy data may be used as a reference in the process of stimulus selection or for comparing identification accuracy on different tokens of the same type of sound across studies. However, accuracy values might vary for a different type of task (e.g., free identification). A complete listing of the original track numbers, response labels, and accuracy scores is given in the Table B1 below.

\section{Method}

Stimuli. Sixty familiar environmental sounds were selected from an extensive CD library of environmental sounds commonly used in television and radio postproduction (SoundIdeas: General 6000). The original sounds were stereo recordings stored as digital audio tracks. They were converted into .wav files sampled at $44100 \mathrm{~Hz}$ and quantized at 16 bits. For the purposes of this study, only left-channel signals from each selected original file were used. The sounds were also shortened in duration when the length of an original sound was greater than 10 secs. Care was taken to preserve any onset and offset information. Deletions were made only on redundantly repeating portions of each edited sound (e.g., car engine idling). To conform to the requirements of the larger study, stimuli were also bandpass filtered between 300 and $5500 \mathrm{~Hz}$, using a 6th order Butterworth filter, and then were additionally filtered with a 6 th order low-pass elliptic filter with a $5000-\mathrm{Hz}$ cutoff. The stimuli were further processed to include a linear $15-\mathrm{msec}$ amplitude ramp at the beginning and the end of each file.

The selected sounds represented a variety of sound sources and included (1) human and animal vocalizations and bodily sounds, (2) mechanical sounds of interacting inanimate solids, (3) water-related sounds, (4) aerodynamic sounds, and (5) electric and acoustic signaling sounds. Many of these sounds were also similar to the types of sounds used in previous environmental sound research with normally hearing (Ballas, 1993; Gygi et al., 2004; Marcell et al., 2000) and hearing-impaired listeners (Owens et al., 1985). Response labels denoting sound sources were selected from open-set responses given to each sound by 10 native English speakers during pilot testing.

Listeners. Sixty-five listeners took part in the experiment. Twenty-one listeners were male, and 44 were female. Forty listeners were native speakers of English, and 25 were fluent but nonnative speakers of English. All 65 participants passed a hearing screening at $25 \mathrm{~dB} \mathrm{HL}$ on at least one ear. The age of the participants ranged from 18 to 47 years, with a mean participant age of 29 years.

Procedure. The listeners were tested in a closed-set response format. They were provided with a description of the categories of environmental sounds they would hear and were given verbal examples of environmental sounds. Next, they were pre- sented with nine tokens of undistorted and spectrally degraded environmental sounds not included in the test stimulus set. The listener's task was to select the best name for the source of each sound he/she heard from a list of 60 labels displayed on the screen in alphabetical order.

Prior to experimental testing, the listeners were trained to enter their responses, using the experimental interface, and were familiarized with each response label and its position on the screen. During the training session, the name of each of the 60 stimuli was displayed on the screen, and each listener had to respond to it as if the stimulus were presented aurally.

Each listener was tested individually in a quiet room. Stimulus presentation was conducted using a custom-built computer program. Every listener heard 120 sounds. The first 60 environmental sounds were spectrally degraded at various levels, as described in Shafiro (2004), and the following 60 sounds were band-limited according to the specifications described above. Presentation order was randomized for each stimulus set. The stimuli were presented to the participants binaurally via Sennheiser HD 414 headphones at listening levels that ranged from $88 \mathrm{~dB}$ SPL for the most intense sound to $67 \mathrm{~dB}$ SPL for the least intense one. After the presentation of a new stimulus, every listener had an option to hear the stimulus once again before indicating his/her response. A typical experimental session took approximately $1 \mathrm{~h}$.

\section{Results}

Identification scores were analyzed to determine whether the listeners were familiar with the test sounds and could identify their sources. The average identification accuracy of the 60 band-limited sounds across all 65 listeners was $96 \%$ correct, with a standard deviation of $12 \%$. Apparently, limiting the sounds' frequency range to a 300 to $5500-\mathrm{Hz}$ bandwidth did not have a substantial effect on identification performance. The accuracy analysis of individual sound tokens revealed that 53 of the 60 sound stimuli were identified at $90 \%$ correct or above. The lowest mean accuracy score for any undistorted stimulus was $82 \%$ ("water bubbling"). The high-accuracy scores on original sounds suggest that all the listeners were familiar with the vast majority of the test sounds. The mean identification accuracy of the male listeners was $97 \%$, whereas the mean accuracy of the female listeners was $95 \%$, with standard deviations of $3.3 \%$ and $4.7 \%$, respectively. However, a median test demonstrated that the $2 \%$ difference in the mean accuracy of the males and the females was not significant $\left(\chi^{2}=0.06, p>.5\right)$. There was also a small difference in mean identification accuracy between native and nonnative English speakers, with natives scoring $98 \%$ and nonnative participants scoring $96 \%$ on unprocessed sounds, with standard deviations of $4.4 \%$ and $3.9 \%$, respectively. The results of a median test revealed that this small difference in accuracy between native and nonnative English participants was, nevertheless, significant $\left(\chi^{2}=6.67, p>.05\right)$. 
APPENDIX B (Continued)

Table B1

Identification Accuracy of 60 Band-Limited Sounds

and Their Audio Track References in the SoundIdeas:

General 6000 Catalogue

(http://www.sound-ideas.com/pdf/6000.pdf)

\begin{tabular}{|c|c|c|c|}
\hline Sound Source Label & $\begin{array}{l}\text { Identification } \\
\text { Accuracy (\%) }\end{array}$ & $\begin{array}{l}\text { SoundIdeas } \\
\text { CD Number }\end{array}$ & $\begin{array}{c}\text { CD } \\
\text { Track Number }\end{array}$ \\
\hline Airplane flying & 98 & 6002 & $22-1$ \\
\hline Baby crying & 98 & 6032 & $1-1$ \\
\hline Birds chirping & 100 & 6003 & $3-1$ \\
\hline Biting, chewing apple & 100 & 6032 & $14-4$ \\
\hline Blowing nose & 92 & 6032 & $27-5$ \\
\hline Bowling strike & 85 & 6031 & $23-2$ \\
\hline Brushing teeth & 98 & 6032 & $3-1$ \\
\hline Burp & 97 & 6032 & $4-1$ \\
\hline Camera taking picture & 98 & 6010 & $45-5$ \\
\hline Car horn & 98 & 6006 & $58-2$ \\
\hline Car starting & 100 & 6006 & $10-1$ \\
\hline Child coughing & 98 & 6032 & $8-9$ \\
\hline Church bells & 97 & 6010 & $23-1$ \\
\hline Clapping & 100 & 6032 & $5-2$ \\
\hline Clearing throat & 94 & 6032 & $40-1$ \\
\hline Clock ticking & 98 & 6020 & $52-1$ \\
\hline Cork popping from bottle & 88 & 6020 & $7-1$ \\
\hline Cow mooing & 100 & 6003 & $48-2$ \\
\hline Dog barking & 100 & 6003 & $52-1$ \\
\hline Dog panting & 86 & 6003 & $58-3$ \\
\hline Door closing & 97 & 6018 & $23-1$ \\
\hline Doorbell & 98 & 6018 & $7-2$ \\
\hline Footsteps & 95 & 6016 & $1-1$ \\
\hline Glass breaking & 98 & 6039 & $68-1$ \\
\hline Heartbeat & 98 & 6039 & $75-1$ \\
\hline Helicopter flying & 97 & 6019 & $26-1$ \\
\hline Horse neighing & 97 & 6003 & $67-3$ \\
\hline Horse trotting & 98 & 6003 & $76-2$ \\
\hline Ice cubes into glass & 100 & 6020 & $61-1$ \\
\hline Jackhammer & 92 & 6011 & $15-1$ \\
\hline Machine gun & 97 & 6025 & $13-1$ \\
\hline Man drinking & 86 & 6032 & $11-1$ \\
\hline Man gargling & 95 & 6032 & $17-1$ \\
\hline Man panting & 98 & 6032 & $2-2$ \\
\hline Man yawning & 98 & 6032 & $43-2$ \\
\hline Page turning & 94 & 6028 & $16-4$ \\
\hline Ping-pong ball & 97 & 6031 & $55-2$ \\
\hline Pool balls colliding & 95 & 6031 & $19-4$ \\
\hline Pouring soda into cup & 98 & 6020 & $13-1$ \\
\hline Rooster crowing & 98 & 6003 & $28-1$ \\
\hline Shoveling dirt & 97 & 6037 & $2-1$ \\
\hline Siren & 100 & 6015 & $69-1$ \\
\hline Snoring & 97 & 6032 & $37-1$ \\
\hline Stone splashing water & 97 & 6035 & $10-3$ \\
\hline Telephone busy signal & 100 & 6037 & $44-5$ \\
\hline Thunder & 100 & 6036 & $1-1$ \\
\hline Toilet flushing & 97 & 6031 & $98-1$ \\
\hline Train in motion & 97 & 6033 & $97-1$ \\
\hline Train whistle & 97 & 6033 & $54-3$ \\
\hline Typing on keyboard & 98 & 6028 & $38-3$ \\
\hline Water bubbling & 82 & 6010 & $40-1$ \\
\hline Water draining & 86 & 6021 & $68-1$ \\
\hline Water dripping & 98 & 6021 & $69-1$ \\
\hline Water running & 89 & 6021 & $67-1$ \\
\hline Whip & 92 & 6037 & $91-1$ \\
\hline Wind blowing & 94 & 6036 & $66-1$ \\
\hline Woman laughing & 100 & 6032 & $25-7$ \\
\hline Woman sighing & 100 & 6032 & $33-1$ \\
\hline Woman sneezing & 98 & 6032 & $36-4$ \\
\hline Zipper & 100 & 6037 & $99-10$ \\
\hline
\end{tabular}




\section{APPENDIX C \\ Characteristics and Structural Elements of a Research-Oriented Database of Environmental Sound Recordings}

In addition to comprising a large collection of sound types and tokens, a research-oriented database of environmental sound recordings should have a number of other desirable characteristics, as described in the body of this article. Overall, information provided for each sound in this database should be sufficiently detailed to satisfy the requirements of peerreviewed journals. Some of the necessary information about files in the database can be gleaned directly by special wave analysis software; other information will have to be provided by the individuals who submit the sounds.

In order for users to be able to locate the sounds they want, a keyword search and a category search would be useful. Key- words searches would look in the name of the sound file, the description, and the recording fields. When a sound is entered in the database, it will be assigned to several categories, describing the physical event that produced the sound, the context of the sound, perceptual attributes, or possibly some features of the acoustics, such as "jungle sound," "noisy rhythmic sound," "menacing sound," or "bat hitting ball." If more detailed information is available, it might be desirable to be able to search on a criterion such as "sounds used in psychophysical studies."

The structural description of an environmental sound database designed for research purposes is illustrated below in Table C1, using one sound (i.e., "rooster crowing") described in Appendix B.

\section{Table C1}

\begin{tabular}{|c|c|}
\hline Sound file name: & BirdsRooster.wav \\
\hline Sound label(s): & Rooster crowing \\
\hline \multicolumn{2}{|l|}{ Sound categories: } \\
\hline 1. & Rooster, single call \\
\hline 2. & Bird, morning call \\
\hline 3. & Animal \\
\hline Sound-source: & $\begin{array}{l}\text { Rooster crowing (additional sound source } \\
\text { details are not available for this sound but } \\
\text { would be desirable for other sounds). }\end{array}$ \\
\hline Recording quality (on a 1 to 7 scale): & 7 \\
\hline File origin: & $\begin{array}{l}\text { The file was obtained from SoundIdeas } \\
6000 \text { series. CD \# } 6003 \text {, Track \# } 28-1 \text {. } \\
\text { It was converted from CD audio format. }\end{array}$ \\
\hline Submitted by: & $\begin{array}{l}\text { Valeriy Shafiro } \\
\text { (valeriy_shafiro@rush.edu) }\end{array}$ \\
\hline Recording details: & $\begin{array}{l}\text { Not available for this sound. (Ideally, would } \\
\text { include type of equipment used, distance } \\
\text { from the source, recording environment, } \\
\text { and recording date). }\end{array}$ \\
\hline \multicolumn{2}{|l|}{ Usage history: } \\
\hline Citation & $\begin{array}{l}\text { Shafiro, V. (2004). Perceiving the sources of } \\
\text { environmental sounds with a varying number } \\
\text { of spectral channels. Unpublished doctoral } \\
\text { dissertation, CUNY, New York. }\end{array}$ \\
\hline Behavioral data available: & Yes \\
\hline Number of downloads: & 0 \\
\hline \multicolumn{2}{|l|}{ File and waveform statistics: } \\
\hline File format (current): & PCM .wav \\
\hline File size: & $153 \mathrm{~KB}(156,972$ bytes $)$ \\
\hline Sampling rate: & $44100 \mathrm{~Hz}$ \\
\hline Quantization depth: & 16 bits \\
\hline Duration: & $1.779 \mathrm{sec}(1779 \mathrm{msec})$ \\
\hline Number of channels: & Mono \\
\hline DC offset: & 0 \\
\hline Number of clipped samples: & 0 \\
\hline RMS (in dB): & $-19.53 \mathrm{~dB}$ below maximum $(0 \mathrm{~dB})$ \\
\hline Peak (in dB): & $-6.86 \mathrm{~dB}$ below maximum $(0 \mathrm{~dB})$ \\
\hline Pricing and availability: & $\begin{array}{l}\text { Currently available to licensed users of } \\
\text { SoundIdeas } 6000 \text { Special effects library. } \\
\text { Contact SoundIdeas, Inc. for current prices } \\
\text { (www.sound-ideas.com). }\end{array}$ \\
\hline Comments: & $\begin{array}{l}\text { Licensing arrangements are being made } \\
\text { with SoundIdeas, Inc. to obtain special } \\
\text { prices on recordings used for research } \\
\text { purposes and to streamline sound distribution. }\end{array}$ \\
\hline
\end{tabular}

(Manuscript received December 31, 2003; revision accepted for publication May 31, 2004.) 